\title{
Comparing Learning Speed of New Mazes in Rats with and without Prior Maze Learning Experience
}

\author{
Khosro Rashid ${ }^{1}$, Arezou Delfan Beiranvand ${ }^{2}$ and Mehran Farhadi ${ }^{3}$ \\ ${ }^{1}$ Bu-Ali Sina University \\ ${ }^{2}$ Master of Art in Educational Psychology \\ ${ }^{3}$ Bu-Ali Sina University \\ ${ }^{1}$ khosrorashid@yahoo.com, 2arezou.delfan14@gmail.com
}

\begin{abstract}
The purpose of this study was to compare the learning speed of new mazes in rats with and without prior Maze learning experience. In the present study, 14 female rats were randomly assigned in two groups, experimental and control (each group consisting of 7 rats). Then, 12 different Mazes were designed and built (although different in shape, they were equal with respect to the level of complexity). The experiment was conducted in two phases. In the first phase; the experimental group started learning Mazes number 1 to 8 , while the control group did not experience these 8 Mazes. In the second phase, both experimental and control groups started gaining experience in Mazes number 9 to 12. The results showed that in learning Mazes 9 to 12, the average time spent and the number of trials was significantly lower in the experimental group than control group. This finding indicates that rats with prior learning experiences learn faster than the rats without prior learning experiences. Moreover, the results showed that rats with prior learning experiences tend to learn with less learning trials than rats without learning experience. Generally, the results revealed that prior learning experiences with a situation or stimulus could positively affect later learning. Therefore, prior experiences have a significant role in the learning of new situations, despite of the differences between two.
\end{abstract}

Keywords: Prior experiences; prior Learning; Maze learning; similar elements model; general principle model

\section{Introduction}

Learning is mostly defined as a useful process in which the learner actively functions by approaching the information, relating the information to his prior knowledge, and controlling and directing his own learning [1]. The study of learning is one of the most important fields in psychology [2]. Most of the behaviors (particularly in human) are the result of learning, so that if it was possible to remove the learned responses, a few behaviors would exist and the living creatures were not able to learn. Furthermore, learning does not merely belong to human beings, rather, other creatures (for instance, worms) can also learn. However, most of the studies in the field of learning are conducted using animals like rats) [3].

But what happens in the process of transferring? Actually, according to the fact that actual learning purpose is only realized when the learning transfer occurs appropriately, this concern has long been discussed that "how does learning transfer from one situation to the other?" Thus, the concept of transfer has long been investigated in psychological studies $[4,5]$. So that virtually all education programs are based on the fundamental premise that humans can apply what is learned in one situation to other situations [6]. Brown and Campione [7] believe that the issue of 'transfer' in the history of psychology, particularly the psychology of learning is stable, but unfortunately less understood. In 
fact, despite of the practical needs of education to the transfer process [3], most of the time promising types of transfer do not occur and this led to numerous research activities in the field of transfer, the concept was first introduced by Thorndike and Woodworth.

They sought to answer the question of how individual's learning transfer from one context to other context. Does transfer is based on the similarity of the contexts or it is the result of the strengthening a mental function associated with other functions? Thorndike and Woodworth [4] stated that transfer takes place when similar method and content exist between the two situations, so that what we have learned in one situation might be useful in the second situation. Accordingly, to solve the issue of learning transfer, the model of similar elements was formed [8]. According to the theory of elements, learning transfer is a certain concept and occurs when part of the final task has a number of elements that has been learned in the first task. For example, the transition from mathematics to physics takes place when they are common in the elements such as symbols, formulas, equations and numerical calculations [9]. Holding [10] noted that if the assignment is similar in both teaching and transfer field, practicing the final assignment by the students during teaching tend to facilitate and transfer would take place in a proper way. The similar elements model was supported by Osgood's research [11]. Today, Thorindyk's observations are evident in studies such as D'Andrade, 1982; Griggs \& Cox, 1982; Manktelow \& Evan, 1979; Reich \& Ruth, 1982; and Fong \& Nisbett, 1991. Ormrood [12] explains four principles of transfer:

1- When stimulus-response is similar in two situations, maximum positive transfer occurs; for example in learning two similar languages such as Spanish and Latin.

2-With similar stimulus and different responses, some positive transition occurs.

3-When stimulants are similar but respondents are different, negative transition occurs (for example, a teacher learns skills related to students' teamwork and subsequently interferes with the level of responses required for the student).

4- When both stimulus and response are different, transition does not occur. For example, learning the physical responses by the teacher does not help the development of teaching methods for the classroom.

In General, the similar elements model in its best condition leads to close transition, but does not lead to the combination and integration of data across different domains [13]. Meanwhile, this model has a general dominance over curriculum and books in the field of transfer and is still the focus of attention, and probably this is why some researchers suggest that similar elements model had the greatest impact on twentieth century education [14].

However, the similar elements model has been criticized for its inability to explain different forms of transfer. Moreover, concerning the learning transfer, this theory fails to account for the similarity of the two assignments [15]. Kintsch [16] stated that based on the available evidence, the theory of similar elements is a low empirical generalization. Since this theory describes the conditions under which different types of transfer makes apparent, but fails to account for the psychological processes that are responsible for transmission of behavior. Whereas, a theory must be able to determine the mental processes that support the observable behavior. Thus, Charles Judd seriously challenged the similar elements model in a classical study in 1908. According to his study, Judd assumed that the transfer does not occur only on the basis of similar elements, but can occur through understanding the abstract principles underlying a phenomenon in situations in which similar elements are not obvious. In other words, a general abstract principle can be transferred to certain and different events. Thus, Judd proposed the general transfer principle based on his point of view and stated that the transition from one stimulus to another is due to abstract general principles underlying a phenomenon. In this model, the transfer is considered to be more abstract [17].

In Judd's classical experiment [9], the expert gives the required instructions and guidance to the experimental group (whose work was throwing darts at the target point 
underwater), while the control group received no instruction or guidance but were busy practicing (throwing darts at the target point underwater). Transfer test included the successful hitting to the target point. Results showed that the experimental group performed better on the transfer test compared to the control group. According to the general principle, attitudinal and directional characteristics of the learner (such as motivation) are important factors in the transition. The general principle transfer model assumes that the underlying general and abstract principles are transferred, not the perceived similarity of the mechanisms [13].

According to Ausubel's [19] theory, when new materials are relevant to the previously learned materials, meaningful learning occurs and learning transfer is faster. So, the prior learning experiences is one of the factors that facilitate the transfer of learning, because transfer refers to the impact of prior learning on current and future learning, and how prior and current learning can be applied in new and similar situations [13]. In other words, learning transfer implies that we learn from our prior experiences in new and similar situations [13].

It means prior knowledge of the learner is important in learning new materials [20]. In fact, prior knowledge, i.e., previous experiences are the prerequisite for the structure of knowledge and individual learning outcomes [2]. For example, Piaget's theory and Gestalt theory both suggest that previous experiences affect future experiences. Several studies have been conducted on humans on the role of previous experiences. For instance, Lany, G'omez and Gerken [22] carried out a study on the role of prior experience in language acquisition. They realized that learner's prior experiences facilitate the new language learning. Lany's [23] study concerning the role of previous experience in language acquisition indicates that previous experience can bootstrap the acquisition of the complex structure of language. Thereby, it can be said that "experience" or "previous experience" is of significant importance as the basis for future learning, particularly learning transfer in new situations.

However, each of these transfer theories emphasize on one aspect of transfer process and it could lead to an educational conflict between transfer models, and on the other hand could lead to an uncertainty in planning learning assignments for the effective educational efforts.

Therefore, the present research can also be considered in line with this issue (a response to determine the nature of knowledge transfer in education based on past experience as a basis for future learning). But, in this line, the specific goal of this research is to study that with changing the mazes, what happens in the performance of experimental and control groups rats? Since, this study seeks to investigate whether rats with prior learning experiences do learn better the new Mazes than un-experienced rats? Thereby, the present study tests two different hypotheses: 1 . Rats with different maze learning experiences learn new mazes faster than un-experienced rats, 2. Rats with different Maze learning experiences learn a new maze with less learning than unexperienced rats.

\section{Materials and Methods}

\subsection{Subjects}

The subjects were 14 white (female) rats. The approximate weight of these animals was 250 grams and their age was 90 days (three months). They were selected from the breeding and reproduction laboratory of Faculty of Sciences in Bu-Ali Sina University. Each of these rats was placed separately in small iron cages (one rat was placed in each cage). The lighting for the lab was set based on a light cycle of 12 hours light and 12 hours darkness. The light was turned on at $8 \mathrm{AM}$ and turned off at 8 PM. Furthermore, to 
reduce the probable anxiety in rats and also make them acclimatize to the researcher, the researcher stroked and played with them for 10 minutes in 5 days.

\subsection{Instruments}

The instrument used in this study was a researcher-made square maze (named DR ${ }^{1}$ Maze). The maze is built in such a way that different mazes with different directions and shapes can be created on one base. Finally, 12 different mazes were designed and were built in each of the experiments. Despite differences in form, all 12 mazes were similar in terms of complexity: The length of path in all Mazes $207 \mathrm{~cm}$, the number of obstacles or dead-ends were 24 , and the length of each obstacle was $20 \mathrm{~cm}$. Length and width of the maze was $137 \mathrm{~cm}$, the width of path (i.e., path size in twists and turns) was $8 \mathrm{~cm}$, and the height of maze's walls were $12 \mathrm{~cm}$. Moreover, entrance place and shape (starting point) and exit part (end point/reinforcement point) were different in each maze. For instance, in maze number 1 (Figure1), the entrance path is like "I" and the exit path is like "T". Furthermore, in order to prevent rats jumping out of the Maze, a big glass were put on the mazes. In order to prevent the rats from using environmental signs, all around the room was wrapped with white paper and the location of the camera changed in each trial so that in early learning trials, rats would not move through the mazes by learning these signs.

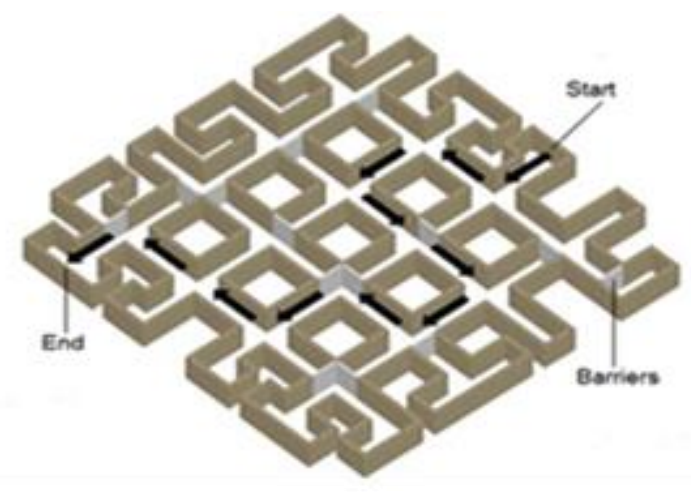

Figure 1. The Sample of Mazes used in this Study

\subsection{Method}

In the present study, the research design was experimental (posttest control group design). The population of the study consisted of 14 white rats selected from the laboratory of the Faculty of Sciences in Bu-Ali Sina University that were assigned to two experimental and control groups (each consisting on 7 rats). In the sampling procedure, rats were randomly selected and assigned to two groups of experimental and control. Moreover, the time span for rats' starvation to learn the maze was nearly 24 hours. Maze learning in the present study was that a rat should move through a maze from the start to the end, repeatedly, three times, and without mistake- without entering the dead ends. Learning speed criterion and the number of learning trials were also measured. Learning speed is defined as the time span required for the rats to move from the start to the goal and learn. Besides, the number of trials is defined as the number of times that a rat should move from the start to the end so that it can pass through the Maze three times repeatedly without mistake. To conduct the experiment, each rat was put in the entrance, and as it reached to the goal (reinforcement), it was brought off the maze by the researcher.

The type of reinforcement used in the study was "white plate", i.e., a kind of special food for the rats. The experiment was conducted in two phases, in the first phase the

${ }^{1}$-Delfan-Rashid 
experimental group started learning mazes number 1 to 8 , while the control group did not experience these 8 mazes. Besides conducting the preliminary things (such as cleaning the maze, setting the camera, setting the temperature, setting the lighting based on lighting cycle of 12 hours light and 12 hours darkness), for example, the researcher put rat number 1 in the maze entrance, and brought it off as it reached the goal. Then, before putting rat number 1 in maze 1 for the second time, the researcher cleaned the rat's urine and feces in the maze (this was done in all learning trials), set the camera to record all parts of the maze in each learning trials, and changed its place. Moreover, in each learning trials, some food was put in the exit. Albeit, in all learning trials in maze (also round-the-clock), water was put beside the food.

Then, the rat was put in the maze for the second time, and was brought off the maze by the researcher as it reached the goal. This procedure continued, until the rats learned the maze (for the third, forth and " $\mathrm{N}$ " number of learning trials). After learning maze 1 by the rat number 1, using the same procedure, the next rats 2,3,4,5,6,7,8 were put in the mazes respectively. That is, for learning all Mazes this procedure was carried out. In the second phase, both experimental and control groups started gaining experience in mazes number 9 to 12 . Furthermore, all the procedures that were taken for the experimental group in mazes 1 to 8 , were also carried out for the control group in mazes 9 to 12 as well as the experimental group in the second phase of the study. Moreover, learning maze number 1 for the experimental group and maze number 9 for the control group lasted for 5 days, while learning the other mazes took place daily. In order to prevent the rats from using other environmental signs, all around the room was wrapped with white paper and the location of the camera would be changed in each trial so that in early learning attempts, rats would not move through the mazes by learning these signs.

\subsection{Data Analysis}

In the present study, in order to investigate and examine the hypothesis, independent samples T-test and Mann Whitney U test were utilized.

\section{Research Findings}

As shown in Table 1, the mean time spent by the experimental group (6.79 seconds) was lower than the control group(16.26), and also the number of learning trials for the success in maze learning is lower in the experimental group (179 trials) than the control group(455 trials).

\section{Table 1. Distribution of Maze Learning Data based on the Time in Seconds} and Trials (in Mazes Number 9 to 12)

\begin{tabular}{|l|c|c|c|c|}
\hline \multicolumn{1}{|c|}{ Groups } & $\begin{array}{c}\text { number of } \\
\text { trial }\end{array}$ & Average time & $\begin{array}{c}\text { The standard } \\
\text { deviation }\end{array}$ & $\begin{array}{c}\text { The standard error } \\
\text { of the mean }\end{array}$ \\
\hline Experiment & 179 & 6.79 & 4.645 & 347 \\
\hline Control & 455 & 16.26 & 23.751 & 1.113 \\
\hline
\end{tabular}

In Table 2, Independent-samples t-test indicated a significant difference between the experimental and control groups regarding the time spent for learning the new mazes $(\mathrm{P}<0.01)$, the experimental group needs less time to learn new mazes than the control group. To put it differently, prior learning experiences increased the learning speed of new mazes $(\mathrm{P}<0.01, \mathrm{df}=535, \mathrm{~T}=8.107)$. 
Table 2. T- Test to Compare Learning Speed (Time in Seconds) in the Mazes Number 9 to 12 for Experimental and Control Groups

\begin{tabular}{|c|c|c|c|c|c|c|c|c|c|}
\hline \multicolumn{6}{|c|}{ Levene's Test for Equality of Variances } & \multicolumn{4}{|c|}{ t-test for Means comparison } \\
\hline \multirow[t]{2}{*}{ Time } & \multirow[t]{2}{*}{ f } & \multirow[t]{2}{*}{ sig } & \multirow[t]{2}{*}{$\mathrm{T}$} & \multirow[t]{2}{*}{ df } & \multirow[t]{2}{*}{ sig } & \multirow[t]{2}{*}{$\begin{array}{l}\text { Mean } \\
\text { Difference }\end{array}$} & \multirow[t]{2}{*}{$\begin{array}{l}\text { Std.Error } \\
\text { Difference }\end{array}$} & \multicolumn{2}{|c|}{$\begin{array}{l}95 \% \text { Confidence } \\
\text { Interval of the } \\
\text { Difference }\end{array}$} \\
\hline & & & & & & & & Upper & Lower \\
\hline $\begin{array}{l}\text { Equal } \\
\text { variances } \\
\text { assumed }\end{array}$ & 61.010 & .001 & -5.290 & 632 & .001 & -9.466 & 1.789 & -12.980 & -5.952 \\
\hline $\begin{array}{l}\text { Equal } \\
\text { variances } \\
\text { not } \\
\text { assumed }\end{array}$ & & & -8.116 & 533.716 & .001 & -9.466 & 1.166 & -11.757 & -7.175 \\
\hline
\end{tabular}

As shown in Table 3, rank mean for the experimental group, regarding the learning trials in Mazes 9 to 12, was much lower than the control group (190.10 Vs. 368.21).

Table 3. Descriptive Data to Compare the Average (Mean) Ranks (Number of Learning Trials in the Mazes Number 9 to 12) for Experimental and Control Groups

\begin{tabular}{|l|c|c|c|}
\hline Groups & $\begin{array}{l}\text { Number of } \\
\text { trials(N) }\end{array}$ & Mean Rank & Sum of Ranks \\
\hline Experiment & 179 & 34020.50 & 190.06 \\
\hline Control & 455 & 367.64 & 167274.50 \\
\hline Total & 634 & & \\
\hline
\end{tabular}

As can be seen in Table 4, Mann-Whitney $U$ test indicated that the experimental group's ranks were significantly lower than the control group, regarding the number of learning trial in mazes 9 to 12 . In other words, Mann-Whitney $U$ test shows a statistically significant difference between the groups $(17918,000)$.

Table 4. Mann-Whitney U Test for Comparison Ranks (The Number of Learning Trials in the Mazes Number 9 to 12 for Experimental and Control Groups)

\begin{tabular}{|l|l|}
\hline Groups: Experiment and Control & Number of Trials \\
\hline Mann-Whitney U & 17910.50 \\
Wilcoxon W & 34020.50 \\
Z & -11.012 \\
Sig & .001 \\
\hline
\end{tabular}

As shown in Figure 3, the experimental group's rats that have prior learning experiences in mazes 1 to 8 tend to learn new mazes (mazes 9 to 12) with less trial than the control group's. 


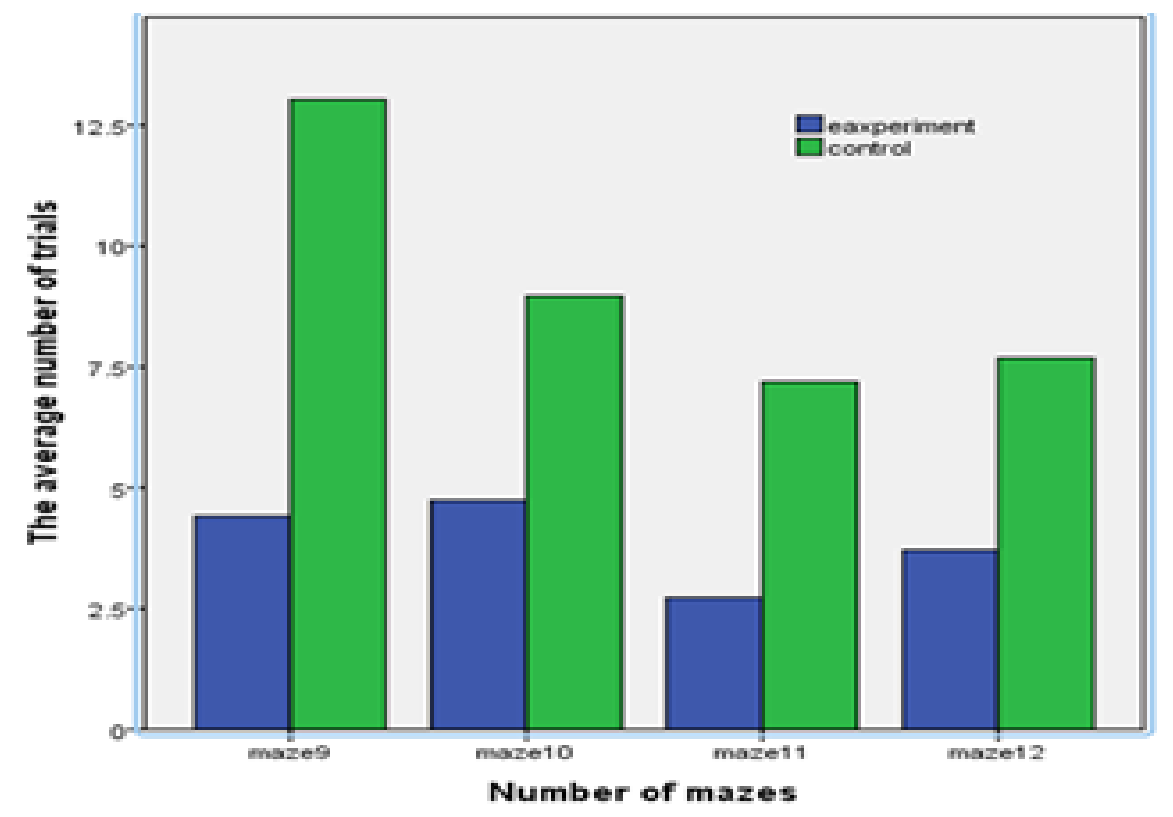

Figure 2. The Columnar Graph to Compare Learning Speed (based on the Number of Trials) in the Mazes Number 9 to 12 for Experimental and Control Groups

As shown in Figure 3, the experimental group (having prior experience in mazes 1 to 8) learned the new mazes faster than the control group. However, it should be noted that only in learning the first maze (number 9), the control group's learning speed was low, and after experiencing the first maze, learning speed in the subsequent mazes was nearly in line with the experimental group's learning speed. In other words, experiencing the first maze had the greatest impact on learning the subsequent mazes, particularly the second maze. Therefore, it can be said that the prior experiences with a stimulus or situation plays a significant role in the transfer process of new situations.

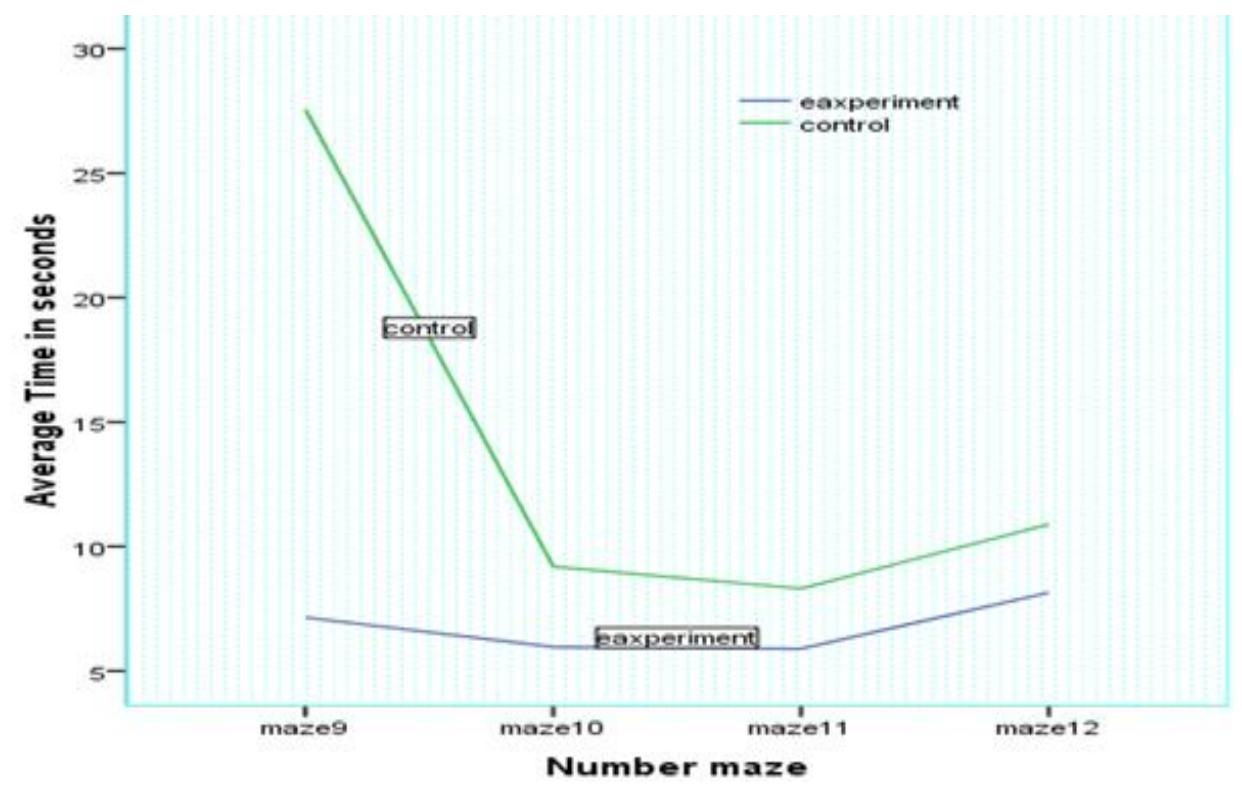

Figure 3. The Line Graph to Compare Learning Speed in the Mazes Number 9 to 12 for Experimental and Control Groups 


\section{Discussion and Conclusion}

Considering the fact that learning transfer in new situations can be affected by prior learning experiences, this study seeks to compare and investigate the learning speed of new mazes. The study revealed that rats with prior experiences with different mazes learn new mazes faster and with less learning trials than un-experienced rats. Moreover, independent-samples t-test indicated a significant difference between the experimental and control groups regarding the time spent for learning the new mazes (mazes 9 to 12). Moreover, the results showed that rats with learning experiences tend to learn with less learning trials than un-experience rats.

Previous experience in a situation or in different situations (stimulus) makes it possible to learn in new situations with less learning trials. These experiences cause the subjects to have better performance in new situations and it seems that helps them to solve the problems with appropriate insight and better strategies. The results of Blujet [25], Tolman and Honezick [24], Spense and Lipit's [26] study are almost in line with the present study. Although they have a different goal in their studies (the effect of prior experiences is evident in their studies. For example, in a study about latent learning, Tolman and Honezick [24] used three mazes (having 14 unites) and three groups of rats (2 experimental groups and one control group). One group of rats did not receive any reinforcement throughout the study. The second group frequently received reinforcement at the end of each trial. While the experimental group received 11 tests in the reinforcement maze and a sudden drop of errors was observed in the subsequent trials, and their performance reached the level of those rats that used to receive reinforcement at the end of each trial. The results of this study showed that prior experiences are effective in later learning. Spense and Lipitt [26] in their study let the rats that were not hungry and thirsty, move through a Y-shaped maze. In this study, water was placed at the right bottom of the maze and reinforcement was put at the left bottom of the maze. In the first stage, when the rats reached one of the two targets in a maze, the researcher put them out of the maze. In the second stage, one group of the rats was deprived of water and the other group was deprived of reinforcement. Therefore, when the rats deprived of water and reinforcement were placed in the maze, the hungry rats, in their first trials, moved towards the side of the maze in which they had found food in prior trials and the thirsty trials moved towards the side in which they had found water previously. Therefore, it can be concluded that prior learning experiences (particularly basic experiences) help the learning transfer and better performance in new situations. Since, prior experiences have a reinforcing nature in new situations. So, when prior experiences are successful and they are efficient in new situations, they lead to better performance in the new environments and such that new situations can be learned faster and with less learning trials (practice or homework). In a study on the field of cognitive map in rats, Tolman [27] indicated that rats that received reinforcement at the end of each trial, reached the learning criteria within two weeks. While rats that spent 11 days without receiving any reinforcement, and only received reinforcement from day 11 to 13 , reached the learning criteria within 3 days. Within the 11 days that these rats spent without food, they gained experience and familiarity by entering into deadlocks and paths. This experience led the rats to learn very fast within these three days and learn the specified paths in the maze with less trials. According to Tolman, these trials used to learn many deadlocks during the unrewarded trials. Therefore, Tolman's[27] results can be considered in line with the present study (although the main purpose of Tolman and also Blujet's studies differend).

This study is different from the above research activities in the main goal it was following. The present study examined the effect of experiencing various mazes on learning new mazes. So, the researchers accept that formal discipline theory is right that by practice we would be more powerful in solving new problems, but what we accept by practice is some basic strategies we learn or make by solving the previous problems. In 
fact, according to us, the rats in this study need less time and do less trials in learning new mazes because the rats step-by-step learn or make some strategies to solve the arrive the end of mazes and take reinforcement. Thereby, the findings of this study suggest that educational system in general and teachers in particular, provide diverse exercises (learning trials) for the students' learning experiences, due to the fact that practicing the learning materials, especially the basic ones, with various methodologies leads to learning the new situations faster, and with less learning trials. But, at the same time the researchers believe that after some trial-error practice (based on behaviorist point of view), we could learn or make some cognitive strategies which help us in solving new problems. So, it could be suggested that according our assumption, stimulus-response or trial-error approach in learning fits with the primary learners, and after some practices, the cognitive processes comes up which lead our problem solving ability, and this is why taking practices is so important in learning.

\section{Acknowledgments}

The authors want to thank the support of Bu Ali Sina University.

\section{References}

[1] C. Tinajero and M. F. Paramo, "Field dependence - in dependence and strategic learning", International journal of educational reaserch, vol. 29, (1998), pp. 251-262.

[2] J. Deese and S. H. Hulse, "The psychology of learning", New York: Mc-Craw-Hill Book company, (1967)

[3] F. E. Weinert and A. Helmke, "The neglected role of individual differences in theoretical models of cognitive development", Learning and Instruction, vol. 8, (1998), pp. 309-323.

[4] E. L. Thorndike and R. S. Woodworth, "The influence of improvement in one mental function upon the efficiency of other functions", Psychological Review, vol. 8, (1901), pp. 247-261.

[5] B. F. Skinner, "Teaching machines", Science, vol. 128, (1958), pp. 969-977.

[6] S. Leberman, L. McDonald and S. Doyle, "The Transfer of Learning Participants' Perspectives of Adult Education and Training", Farnham, UK: Gower, (2006).

[7] A. L. Brown and J. C. Campione, "Three faces of transfer: Implications to early competence, individual differences, and instruction", Advances in Developmental Psychology, vol. 3, no. 143, (1984).

[8] S. M. Cormier and J. D. Hagman, "Transfer of learning contemporary research and application", New York: Academic Press, (1987).

[9] S. K. Mangeal, "Essentials of educational psychology", PHI Learning Pvt. Ltd Psychology, (2006), p.736.

[10] D. H. Holding, "Principles of training", New York: Pergamon Press, (1965).

[11] C. E. Osgood, "The similarity paradox in human learning: A resolution", Psychological Review, vol. 56, (1949), pp. 132-143.

[12] J. E. Ormrod, "Educational psychology:Developing learnrs”, perntic Hall,upper saddle River ,NJ, (1998).

[13] R. E. Haskell, "Transfor of learning:cognition, instruction, and reasoning”, A wolum in the educational psychology series, (2001).

[14] A. Woolfolk and L. M. Nicolich, "Educational psychology for teachers", Englewood Cliffs, NJ: Prentice-Hall, (1980), p. 267.

[15] J. P. Mestre, "Transfer of learning from a modern multidisciplinary perspective", IAP, (2005).

[16] W. Kintsch, "Learning, memory, and conceptual processes", New York: JohnWiley \& Sons, (1970).

[17] C. H. Judd, "The relation of special training and general intelligence", Educational Review, vol. 36, (1908), pp. 42-48.

[18] J. A. McGeoch, “The psychology of human learning: An introduction”, New York: Longmans, (1942), p. 347

[19] D. P. Ausubel, "Educational psychology: A cognitive view", New York: Holt, Rienhart and Winston, (1968).

[20] B. Ertl and H. Mandl, "Effects of individual's prior knowledge on collaborative knowledge construction and individual learning outcomes in videoconferencing", In S. A, (2006).

[21] M. Olson and B. Hergenhahn, "An introduction to theories of learning", Upper Saddle River, NJ: Pearson Prentice Hall, (2009).

[22] J. Lany, R. L. G'omez and L. A. Gerken, "The Role of Prior Experience in Language Acquisition", Cognitive Science, vol. 31, (2007), pp. 481-507.

[23] J. Lany, "The Role of prior experiment in languagh acquisition", A Doctoral Thesis(Doctor of philosophy), The university of Arizona, (2007). 
[24] E. C. Tolman and C. H. Honzik, "Introduction and removal of reward, and maze performance in rats", University of California Publications in Psychology, vol. 4, (1930), pp. 257-275.

[25] H. G. Blodgett, "The effect of the introduction of reward upon the maze performance of rates", univ,calif.publ.psycholo., vol. 4, (1929), pp. 113-134.

[26] K. W. Spence and R. Lippitt, "Latent Learning of a simple Maze problem with relevant needs satiated", Psychological Bulletin, vol. 37, no. 429, (1940).

[27] E. C. Tolman, "Cognitive maps in rats and men", The Psychological Review, vol. 55, no. 4, (1948), pp. 189-208.

\section{Authors}

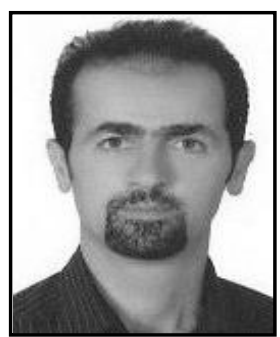

Khosro Rashid has Ph.D in Educational Psychology from Allameh Tabatabai University and was a visiting scholar at Universty of California, Berkeley. He is the member of Psychology department at Bu-Ali Sina University,Hamedan, Iran.

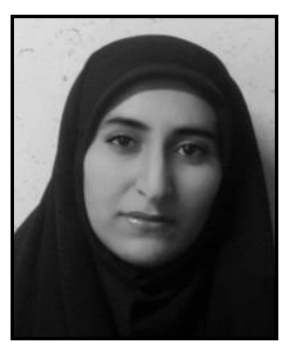

Arezou Delfan Beiranvand has MA in Educational Psychology From Bu-Ali Sina University, Hamedan, Iran.

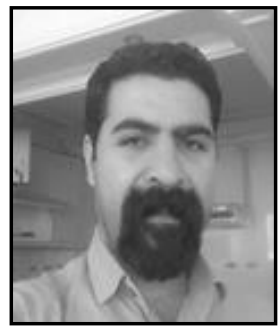

Mehran Farhadi has Ph.D in Health Psychology from Tehran University. $\mathrm{He}$ is the member of Psychology department at Bu-Ali Sina University, Hamedan, Iran 